This is an author-produced PDF of an article published in the journal Research

Studies in Music Education. Copyright SAGE. Citation information:

Grant, Catherine and Low-Choy, Samantha (2020). Social awareness and engagement in undergraduate music students: Generating a foundation for curriculum decisions. Research Studies in Music Education [online version]. https://doi.org/10.1177/1321103X19899170.

\title{
Social awareness and engagement in undergraduate music students: Generating a foundation for curriculum decisions
}

\section{Catherine Grant and Samantha Low-Choy}

Tertiary music institutions, like universities generally, are increasingly recognising the value and importance of a curriculum that fosters social awareness and social engagement in students. This article reports on a mixed-methods research project that investigated the nature and extent of social awareness and engagement among undergraduate students at one Australian tertiary music institution. Through a survey methodology, the research sought to understand students' interest in, and awareness of, pressing contemporary social issues, as well as their prior, current, and perceived potential future engagement in those issues. A clear understanding by educators, researchers, and tertiary music institutions of the nature and degree of undergraduate students' social awareness and engagement is an important and arguably necessary foundation for expanding and improving socially engaged teaching and learning initiatives.

\section{Keywords}

higher education; music education; social justice; music education curriculum; curriculum; social responsibility; undergraduate music education

\section{Introduction}

In recent years, tertiary music education has copped some criticism for being "out of touch with the pressing problems and issues faced by students in their everyday lives" (Elliot, Silverman, \& Bowman, 2016, p. 14). In a narrative about her trajectory as a music educator, Whyte describes how she "would sit in my music education classes at university thinking to myself, 'Is this it? Is this all we hope to do here; to get students to play in tune and in time? Is mere musical achievement the objective?"' (2009, p. 319). Teachers and institutions are increasingly acknowledging that standard approaches to tertiary music education have "too often" viewed technical excellence as the primary end goal (Elliot, Silverman \& Bowman, 2016, p. 13). This has led to calls for a new educational approach, one in which tertiary music education would, as a matter of course, reach "beyond incomplete musical engagements and into larger and more intertwined social, artistic, and political domains" (Allsup \& Shieh, 2012, p. 47). The calls for a more transformative, outward-looking music 
education align with related calls across the broader university sector, in which universities now largely emphatically agree that they "should be concerned with the idea of social justice and fairness, and that knowledge can be generated and applied for a better social outcome" (Nyland, 2017, p.3).

In the context of these educational shifts, several tertiary music institutions in Australia, the UK, the USA, Canada, and elsewhere have recently commenced or re-invigorated efforts to help students conceive of and practice "music-making as ethical action"- that is, music-making that will empower and transform people and their lives (Elliot, 2012, p. 22). Such efforts may take various forms, from introducing socially oriented approaches to the core curriculum in situ (c.f. Bachen, Brewster, GuerraSarabia, Merritt, \& Schneider, 2015), through to offering community-based educational activities (e.g. Nichols \& Sullivan, 2016), immersive overseas mobility experiences (e.g. Grant, 2018), culturally-oriented pre-service teacher programs (e.g. Miettinen, Gluschankof, Karlsen \& Westerlund, 2018), or intercultural service-learning initiatives (e.g. Bartleet, Sunderland \& Carfoot, 2016). While each approach inevitably involves challenges, the potential overall benefits of such socially engaged curriculum initiatives are many. Music students who have the opportunity to explore issues of real relevance to their lives and worlds are more engaged in learning (Gude, 2007, p. 8). They cultivate greater social awareness: "factual knowledge about important aspects of social system" combined with a capacity to respond appropriately to allied problems (Wani \& Nadeem, 2016, p. 4915). They develop social consciousness: "the awareness that there is more than one valid way to view the world" (Frierson-Campbell, 2007, p. 259). They forge social imagination: the "capacity to invent visions of what should be and what might be in our deficient society" (Greene, 1995, p. 5). Through music, they are enabled "to navigate the politics of identity, opening up possibilities to embrace, trouble, and explore the intersections of identity" (Hess, 2019, p. 61). Ultimately, they are equipped to become change agents, not only critically reflective about current society but empowered to transform it (Whyte, 2009, p. 219).

As tertiary music educators and institutions continue to seek ways to make the curriculum more socially engaged and relevant, it is important to engage and involve students themselves in this process. Doing so may yield dividends in several ways. It could help educators and institutions better understand the prior (including pre-tertiary) experiences and backgrounds of students, which may affect students' levels of inclination, confidence and ability to engage with society through music during their studies; it could help identify those social issues that matter most to students, and why; and it could shed light on any possible reservations or concerns students may have about social engagement during their studies, or in their lives or careers as musicians. In turn, these student-centric understandings have important implications (albeit in complex, non-linear ways, as discussed later this article) for decisions about developing a more socially engaged tertiary music curriculum. Incorporating the student voice into the decision-making process would seem likely to improve the relevance, appropriateness, and therefore ultimately the efficacy of any such curriculum changes.

Despite these likely benefits of research on the student voice, scholarly investigations into this topic from the viewpoint of music students themselves are currently very few. This current article is one of two presenting findings from a research project that explored understandings, perceptions and experiences of social awareness and engagement among undergraduate students at one Australian tertiary music institution. The first article (Grant, 2019) draws primarily on focus group data from the project, and reports on the way participating students envisaged their possible social roles as musicians. The present article is based primarily on the project's survey data; it centres on students' interest in, and awareness of, contemporary social issues, as well as their existing and perceived 
potential future engagement in those issues. The overall research findings from this project are already forming an evidence base, and a provocation, for collegial discussions about ways to advance a more socially engaged learning and teaching agenda at the institution in question. However, we authors hope that this research may also function as a stimulus, methodological model, and foundation for comparable and eventually more in-depth research across the international tertiary music sector that foregrounds the student voice in matters relating to institutional social change agendas ${ }^{1}$. As such, this research sits within, and contributes to, the body of literature known as 'scholarship of engagement', which is considered by Dragne (2007) as "a distinct and important movement in the contemporary practice of higher education" (p. 8) that explores changes in the ways universities are operating to address critical societal issues and contribute to public good (p. 13).

\section{Methodology}

\section{Population}

The institution chosen for this study is a prominent and established Australian urban university-based music and performing arts school with 634 undergraduate and 122 postgraduate students enrolled at the time of data collection (late 2017). It offers degree programs with specialisations in classical music, jazz, opera, popular music, musical theatre, composition, music studies, acting, music technology and music education. In 2017, just under $20 \%$ of all students came from low socioeconomic status backgrounds; $10 \%$ spoke a language other than English at home; 5\% were international students; just under 5\% identified as having a disability; and eight identified as Australian First Peoples (sourced in 2018 from the university's internal 'Planning and Statistics Portal').

Undergraduate students at this institution have some opportunities - mostly elective - to engage with socially oriented activities through the formal curriculum. These include community-based local outreach activities, self-directed project studies, and short-term mobility programs in communities in Indigenous Australia (Bartleet, Sunderland, \& Carfoot, 2016) or overseas (Grant, 2018). Such projects align with the university's aims, as articulated in its Academic Plan 2017-2020 (Griffith University, 2017), to ensure that all graduates, across all disciplines, are "socially responsible and engaged with their communities" (p. 10) and equipped "with the capacity to play an influential role in the world" (p. 12).

\section{Data collection and sampling}

Following ethical clearance ${ }^{2}$, data collection was carried out in August 2017, using a survey methodology. (The wider research project also involved a series of focus groups, whose findings are reported on separately, in Grant, 2019.) Designed using the online tool LimeSurvey, the survey sought to gather a broad sample of qualitative and quantitative data. The sampling pool comprised all 634 undergraduate students enrolled at that time in any degree program, across all year levels and

\footnotetext{
${ }^{1}$ This survey of the social attitudes of music students at university can be viewed as a first study in an ongoing program of research at the nexus between scholarly teaching and social science. This research is a quantitative study, albeit within the tradition of describing mixed methods research as a group of interrelated quantitative and qualitative studies (Cresswell, 2009). It provides a foundation for further qualitative studies that could explore in more detail the themes identified in this survey. In turn, this combination of exploratory qualitative and quantitative studies could provide a basis for a far more comprehensive quantitative study: a survey of student attitudes, potentially "mixed-in" with a parallel qualitative study (for an example of how this could be achieved using a Bayesian statistical approach, see LowChoy, Riley \& Alston-Knox, 2017).
}

${ }^{2}$ GU Ref 2017/2012 
specialisations. On behalf of the researchers, the student administration office sent an email to these students inviting them to participate in the survey, thereby eliminating the pressure to participate that students may have felt if research team members-who are also these students' lecturers and institutional leaders - approached students directly. Survey participation was voluntary. Four small prizes (gift cards) were offered as incentives. Some survey respondents self-identified in order to be able to later receive notification of results; a research assistant anonymised all raw data prior to providing these to the research team for analysis. Feasibly, those students who chose to participate in the survey may be those who are more inclined to engage with their learning in broad (non-musicexclusive) ways; they may also be students at both lower and higher levels of social awareness and engagement, and/or those with strong experiences or opinions relating to the social role of musicians. Given the small sample size from one institution, no claims are made about the external validity of the data, that is, the extent to which the results are generalizable across the undergraduate music student population, and across contexts (Wiersma, 2013, p. 2). Rather, as argued above, the significance of the research lies in providing a methodological and epistemological foundation for future in-depth studies within this and other institutions, and across institutions, with possible implications for curriculum and institutional social change agendas.

\section{Conceptual framework and survey design}

Elliot and colleagues point out that "[ $\mathrm{t}]$ he range of social problems on which artistic practice can be brought to bear is immense: violence, religious and ideological conflicts, poverty, starvation, disease, environmental disasters, and gender and racial discrimination, to name but a few" (2016, p. 13). Despite the vastness of the topic, certain social issues (Box 1) and groups of people (Box 2) were selected for specific mention early in the survey tool as a way to orient students to the nature of the kinds of social issues and social concerns under consideration in the research. Examining nuances of how students responded to various questions throughout the survey about these social issues and groups of people also enriched subsequent statistical and qualitative analysis of survey results. These groups of people - all in some way misunderstood or marginalised in contemporary Australian society - and issues of social concern all were chosen with reference to the social justice literature (including Ayers, Quinn \& Stovall, 2009; Benedict, Schmidt, Spruce \& Woodford, 2015). The selection also took into account matters on the contemporary public and political agenda in Australia. Of interest for research purposes was students' levels of awareness, previous experience, and desired future engagement with these and other comparable social issues and groups of people. This directly relates to the research objective: to examine and identify understandings, perceptions and experiences of social awareness and engagement among participating undergraduate students. 
Box 1: Social issues referred to in the survey.

- Australian Indigenous affairs

- Climate change / environment

- Criminal justice

- Cultural diversity

- Disability

- Gender equality and rights

- Global refugee crisis

- International affairs

- Islam and related social issues

- Mental health

- Poverty and social disadvantage

\section{Box 2: Groups of people referred to in the survey.}

- Australian Indigenous people

- Elderly people

- LGBTIQ or gender-diverse people

- Muslim people

- People from culturally diverse backgrounds

- People from low socio-economic backgrounds

- People with disabilities

- People with mental illnesses

- Prisoners

- Refugees

In developing a conceptual framework and data collection tool suitable for a contemporary Australian, music-specific context, the authors also referred to recent instruments and approaches from diverse educational contexts that aimed to gauge the nature and degree of learners' (and teachers') social awareness and engagement. Four studies in particular provided loose inspiration for the design, conceptual framework, and content of the survey tool. While our research focuses on gauging social awareness in the tertiary music context, Bachen, Brewster, Guerra-Sarabia, Merritt, and Schneider (2015) more broadly consider student learning outcomes for an undergraduate program in social justice at Santa Clara University, California, in order to determine an improved approach to social justice learning at tertiary level. In relation to teacher training, Wani \& Nadeem (2016) surveyed 420 higher education teachers in Kashmir (India) using Nadeem-Ijal's Social Awareness Scale, to ascertain and compare participants' level of social awareness (finding that $74 \%$ had a moderate level of social awareness, and 16\% a high level). For pre-service teacher education in Scotland, Pantić (2017) examined existing research tools designed to gauge a teacher's 'agency' in social justice - defined as belief in the purpose of one's pursuit, competency and autonomy to execute this belief, and reflexivity on one's prior performance as a teacher. Finally and in a music-specific context, drawing on collaborative inquiry, participant questionnaires, participant interviews, and curricular units developed by participants, Baxter (2007) sought to evaluate social justice learning outcomes of a tertiary music course at Crane School of Music, State University of New York.

The research intentions of the survey were addressed in four parts, incorporating both open and closed questions. Part 1 gauged the respondents' levels of awareness and interest in social issues and certain social groups. Part 2 gauged levels of prior, current and envisaged future engagement with social issues and with those same groups of people. Part 3 asked respondents about the degree to which they could envisage themselves engaging as a musician with certain social issues ${ }^{3}$. Part 4 comprised demographic data. Parts 1 and 3 included questions that used a 5-point Likert scale, from 'not at all' (1) to 'a great deal' (5), and Part 2 included questions where respondents were asked to rank ten items top to bottom.

\footnotetext{
${ }^{3}$ Part 3 also sought interpretations of what it meant for a musician to be 'socially engaged'. The qualitative findings from this section of the survey warranted in-depth consideration in conjunction with data from the focus groups, which focused on this topic; these are reported upon in Grant (2019). With regard to this Part, then, this article reports primarily on the quantitative analysis of the responses.
} 
To communicate the prevalence of different levels of student interest and experiences, we report summary statistics that are appropriate for our ordinal data, which was obtained via Likert scale and ranked responses (see for example Cleveland, 1985). The median of a variable is the "middle" value and can be interpreted as its "typical" value. It is obtained by sorting all responses from lowest to highest, then finding the middle point, with one half of the responses falling above it, and one half below. Similarly, the lower and upper quartiles "cut" the data into quarters, so are the midpoints of the lower and upper half of responses. The inter-quartile range, being the difference between the upper and lower quartiles, therefore encompasses the middle half of responses. To assess correlation of ordinal variables, we use Spearman's correlation. This measurement between -1 and +1 reflects the kind and degree of association between two variables. The kind of association is determined by whether one variable increases or decreases as the other variable increases, resulting in positive or negative correlation respectively. Stronger association results in correlation close to plus or minus 1 , but where variables operate independently of each other correlation will be near 0 . Correlations between -0.30 and +0.30 are considered weak.

\section{Demographics}

Over 6 weeks, 61 students responded to the survey from a sampling frame of 634 students approached via email. This response rate of around $10 \%$, while relatively low, meets the benchmark set by the Centre for Higher Education Quality, Monash University, Australia (as cited by Nair et al, 2008). The relatively low response rate may reflect the fact that higher education surveys generally have met with declining response rates (Fosnacht, Sarraf, Howe \& Peck, 2017); as those researchers note, low response rates do not necessarily introduce bias to the results or affect data quality. Of those respondents who identified their gender, $55 \%$ were females $(n=29)$ and $40 \%$ were males $(n=21)^{4}$, compared with the relatively lower proportion of females $(45 \%, n=283)$ and higher proportion of males $(55 \%, n=351)$ in the undergraduate cohort in question. Two survey respondents identified as being of non-binary gender. Ages of respondents ranged from 18 to 47, with an average of 20slightly narrower than the cohort range of 16 to 49, which however also had an average age of 20.

Most respondents ( $\mathrm{n}=45)$ were enrolled in the Bachelor of Music (BMus) program; six were studying a Bachelor of Popular Music (BPM), and one a Bachelor of Music Technology (BMuTech); the remaining nine students chose not to provide demographic data. These degree programs have the first, second, and fourth highest enrolments at the institution respectively; response rates per program equate to $12 \%$ of $n=383$ (BMus), $4.9 \%$ of $n=123$ (BPM), and $1.2 \%$ of $n=85$ (BMuTech). No students from the third-ranked program by enrolments - the Bachelor of Musical Theatre - chose to take part, nor any students in the smaller Bachelor of Music Performance or Bachelor of Music Composition programs. Most respondents were in Year $1(n=19)$ or Year $3(n=20)$ of their degree, with few in second year $(n=10)$, and fewer still in Honours $(n=3)$; however, this represents a higher proportional rate of responses by Honours students (total $n=20$ ) relative to the wider cohort, as well as a lower proportional rate of responses from second-year students. The main areas of study represented were classical instrumental $(n=28)$ and classical voice $(n=10)$, which together made up nearly two thirds of the respondents; in order of frequency, other areas included popular music, jazz, composition, and music technology. This is broadly consistent with the wider cohort, in which over two thirds of those enrolled in the largest program, the Bachelor of Music, study classical instrumental or voice.

\footnotetext{
${ }^{4}$ Nine students chose not to answer demographic questions.
} 
The majority of respondents (79\%) described their cultural identity as white Australian ( $\mathrm{n}=42)$, with others identifying as being of Asian-Australian or Asian-European heritage $(n=8)$, or not responding to this question $(n=11)$. No comparable statistics are collected about the undergraduate cohort at large, though $10 \%$ of the wider cohort $(n=65)$ are recorded as speaking a language other than English at home. Five Aboriginal students (and no Torres Strait Islander students) were enrolled at the time of this research; none of these five identified as participating in this research. Institutional records identify $96 \%$ of the wider undergraduate cohort as Australian citizens, and $2 \%$ as international temporary residents. All students who answered the demographic survey questions were Australian residents: that is, none of the 13 international undergraduate students enrolled in this institution at the time of the survey chose to take part in the research.

\section{Findings and Discussion}

Key findings are presented here together with associated discussion, to allow the reader to focus on each topic in depth. To this end, topics are presented in two interrelated sections: students' awareness and interest in social issues; and their prior, current, and perceived future engagement in such issues.

\section{Social Awareness and Interest}

Of the eleven social issues identified to students in the survey tool (Box 1), Mental health was of most interest to respondents: $97 \%(n=59)$ expressed 'a fair amount', 'quite a bit' or 'a great deal' of interest in this issue, and all respondents indicated at least some interest in it (Figure 1). Although respondents were not asked to explain their levels of interest in these social issues, in the case of mental health, it may be reasonable to surmise a link between respondents' high interest and the high and growing prevalence and severity of mental health difficulties among student populations across Australian universities, which exceeds their age-matched peers not undertaking university study (Baik et al, 2017, p. 4).

Other issues on which respondents indicated relatively high levels of interest were Poverty and social disadvantage, Gender equality and rights and Climate change / environment (Figure 1); in these cases, like that of Mental health, respondents may perceive a clear relevance to their own lives or the lives of those they know or encounter. Of least interest to most respondents was Australian Indigenous affairs, for which $41 \%$ of respondents $(n=25)$ indicated 'no' or 'a little' interest. In this case, respondents may not perceive a direct relevance to their own lives. This may also be the case for the other two issues in which few respondents expressed interest, Criminal justice and International affairs (with around 30\% indicating 'no' or 'a little' interest): respondents may have had relatively fewer opportunities to learn about these issues or encounter them on a personal level, compared with (for example) issues relating to mental health, gender, and the environment.

Figure 1 represents respondents' interest in, and (perceived) level of informedness about, social issues. The grey horizontal boxes extend to the minimum and maximum level across all topics, and show that in almost all cases at least one respondent assigned the lowest level $(\mathrm{min}=1)$ or the highest level $(\max =5)$. The only exception was level of informedness about Mental Health issues, where the lowest score was higher than usual, at "A little" $(\min =2)$. For all social issues, the middle set of responses often settled around the centre of the range (Inter-Quartile Range [IQR]=2-4, shown by dark grey shading in Figure 1). However, in some cases, the middle 50\% of students chose responses in the upper end of the range (IQR=3-5): as in interest in Cultural diversity, or informedness about Gender equality and rights. The middle range of students were least informed about Australian 
Indigenous affairs and in Criminal justice ( $\mathrm{IQR}=2-3$ ). The lowest typical response in relation to interest occurred for Australian Indigenous affairs (median=2).
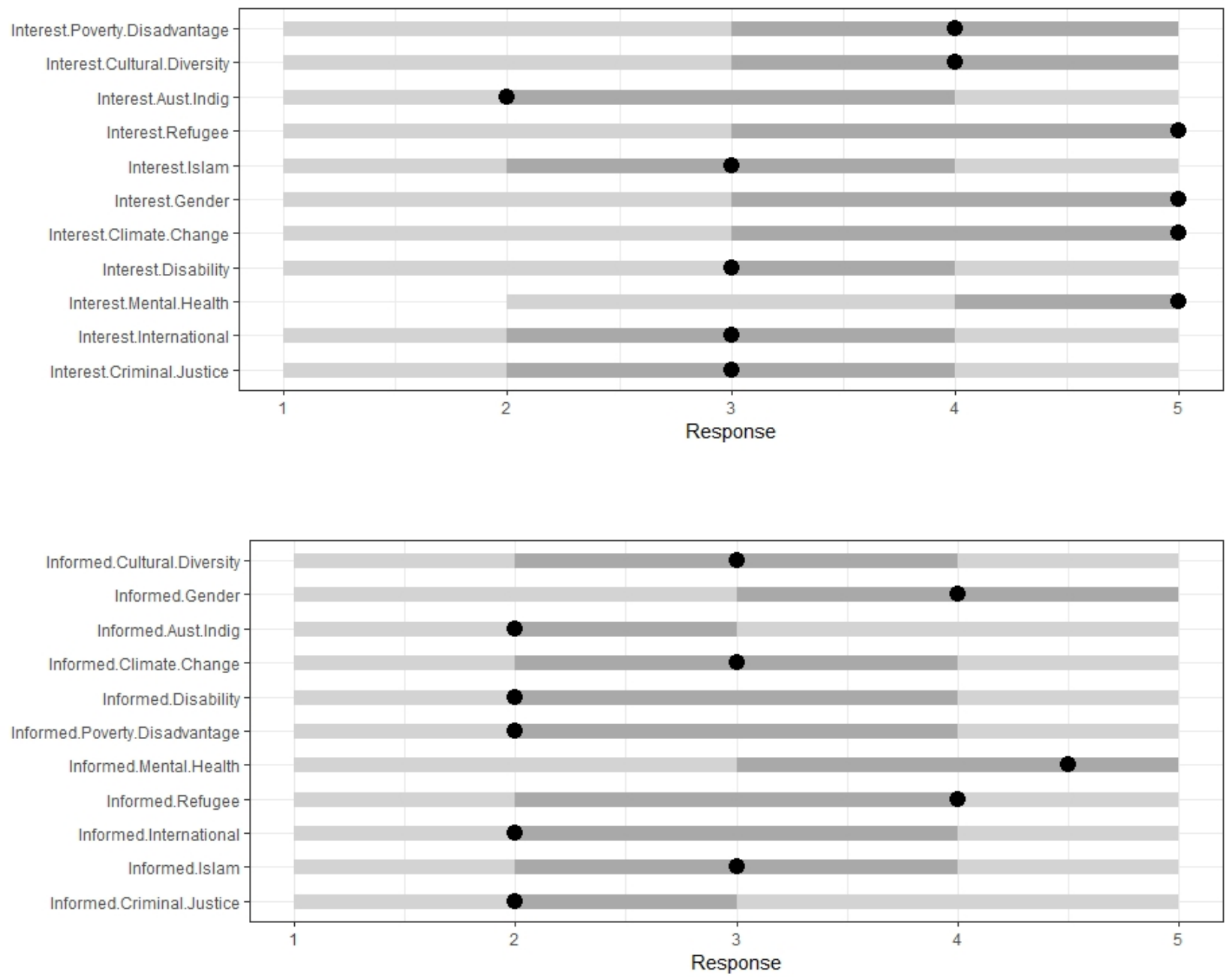

Figure 1. 'Box and whisker' plots (Cleveland 1985) for (a) levels of respondents' interest in specific social issues, and (b) their perceived levels of how well informed they are on those issues. The typical response is the median (circles). The middle 50\% of responses are contained in the Inter-Quartile Range (IQR; dark grey shading). The full range of responses extends from the lowest and highest response from the sampled students (light grey shading).

Respondents reported feeling most informed about Gender equality and rights $(87 \%$ at least 'a fair amount' informed) and Mental health (83\%) — both issues for which there were high levels of interest. They felt least informed about Australian Indigenous affairs (37\%) and Criminal justice (15\%), both issues with low interest levels. Climate change / environment was a further issue revealing a correlation between interest and informedness: students typically felt 'a great deal informed' and 'quite a bit interested' in this issue. However, for Australian Indigenous affairs, the typical responses were 'quite a bit informed' but 'only a little interested', which could arise from a negative correlation between interest and informedness. Poverty and social disadvantage and Cultural diversity were areas with moderate to high levels of interest with less informedness. Further research is necessary to identify any causal relationship between informedness and interest or vice versa. In general across all 
social issues, the trend was for students to feel more informed about them than they were interested in them.

Students' interest and informedness in some pairs of issues (Figure 2) revealed a few strong correlations, with correlations not always evident for other pairs. For example, interest in Poverty and social disadvantage was closely correlated with Cultural diversity in terms of interest (cor $=0.55$ on a scale from 0 to 1 , with higher numbers meaning stronger correlations) but not informedness (cor=0.06). Interest in that same issue of Poverty and social disadvantage was associated with interest in Disability and Australian Indigenous affairs (cor $=0.52,0.51)$ but not informedness on these two issues (cor $=0.20,0.14$ ). This may suggest that students have emerging engagement with these social issues, as their interest in them is outstripping knowledge. The issues of Australian Indigenous affairs, Climate change / environment and the Global refugee crisis are also related in terms of interest (cor $=0.49$ to 0.55 ) and informedness (cor $=0.46$ to 0.60 ). Even more strongly related were students' levels of interest and informedness in Islam and related social issues and the Global refugee crisis (cor=0.64); in this case, a possible link is easier to suggest (with many displaced people originating from Muslim-majority countries; UNHCR, 2018). Interestingly, the strongest alignment was found between interest in International affairs and informedness in the same (cor=0.76), as well as with informedness in the Global refugee crisis ( $\mathrm{cor}=0.65$ ) and Criminal justice (cor $=0.57)$. This potentially contextualises students' interest in the refugee crisis as a justice and global issue. In turn, informedness on Criminal justice or Cultural diversity were each moderately aligned with informedness on Disability, Gender equality and rights, International affairs and the Global refugee crisis. For informedness, the two issues of Islam and the Global refugee crisis became instead more aligned with Poverty and social disadvantage, Cultural diversity and Australian Indigenous affairs.

Overall, interest levels seem to generally be aligned across issues: students with greater (or less) interest in any issue generally exhibit this level for other issues too. There are no pairs of issues with negligible correlation in terms of 'interest' (no areas of very light grey in Figure 2 for such pairs), and none with negative correlation. However, the way that informedness is related across pairs of issues exhibits greater disparity (with light through to dark coloured areas). 

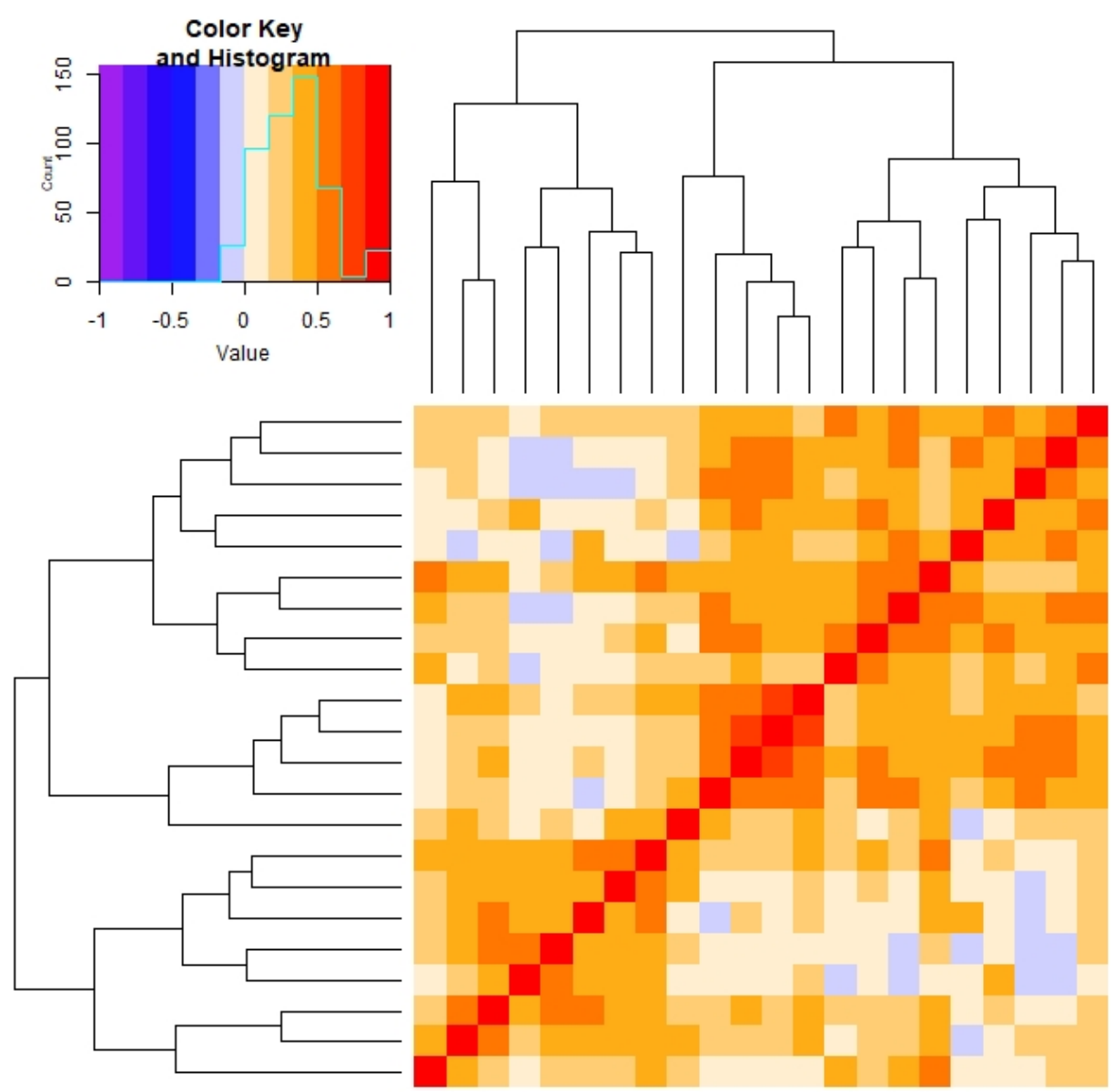

Informed.Gender

Informed.Cultural.Diversity

Informed.Islam

Informed.Climate.Change

Informed.Aust.Indig

Interest.Disability

Informed.Disability

Informed.Poverty.Disadvantage

Informed.Mental.Health

Interest.International

Informed.International

Informed.Refugee

Informed.Criminal.Justice

Interest.Criminal.Justice

Interest.Poverty.Disadvantage

Interest.Cultural.Diversity

Interest.Aust.Indig

Interest.Gender

Interest.Climate.Change

Interest.Refugee

Interest.Islam

Interest.Mental.Health

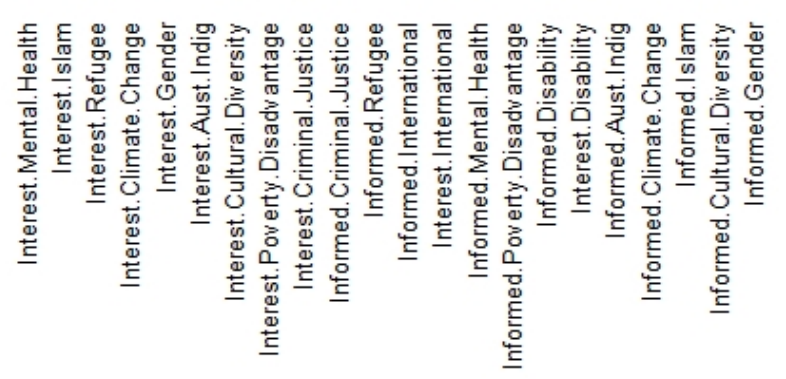

Figure 2. 'Heatmap' visually representing pairwise correlation for respondents' interest in each pair of social issues, and their perceived levels of how well informed they are on those issues. Positive correlations, shaded from dark to light for strong to weak, indicate that as interest or informedness increases for one issue, it increases for the other in the pair. Correlations were measured using Spearman's rank correlation, suitable for Likert scaled data.

Respondents were invited to identify any other social issues they were interested in, beyond those named. A third of respondents $(n=17)$ identified a wide range of issues, including animal rights and welfare; body positivity; children's rights; domestic violence; freedom of expression; human trafficking; LGBTIQ+ rights; individual rights and liberties; racism and xenophobia; religious persecution; and youth enfranchisement. Some responses indicated that certain individuals were interested in a number of social issues:

LGBTQIA Issues, musical genre diversity / music industry diversity, domestic violence issues, appearance-based discrimination and abuse, music industry sexism (under gender 
equality rights category, but I believe it deserves its own category due to its vastness). (Respondent [R] 34)

The famine crisis in Africa. Brexit and the state of the EU. Poverty in America and the growing class division. The political and judicial systems in the US and how they affect black members of the community and the lower classes. (R37)

Overall, these findings may hold high relevance to curriculum matters in the context of the increasing tertiary-sector efforts to promote a sense of social responsibility and social engagement among university students and graduates. This is particularly true given that only $23 \%(n=14)$ of respondents in this study reported learning about social issues through their university education, the least common response among the eight available options. Rather, for those social issues they felt they knew a lot about, respondents reported mostly learning about them through self-education $(84 \%, \mathrm{n}=$ $51)$, the media (77\%), personal experience $(75 \%)$, from their parents $(64 \%)$, through their school education $(62 \%)$, and through friends $(61 \%)$.

\section{Social engagement}

Survey respondents were asked to order ten specified groups of people (Box 3) according to how much they had had to do with them, identifying groups with the most (rank $=1$ ) to least (rank $=10$ ) level of prior engagement. The data captured on groups for each rank was "turned around" to give the rank for each group. Results are summarised in Figure 3, for (a) prior and (b) desired future levels of engagement. Across all respondents, the groups of people that students had had most to do with (that is, those with ranks closest to the top rank of 1) were: people with mental illness (median rank 3); followed by elderly, LGBITQ / gender diverse, those from low socio-economic backgrounds or culturally diverse people (all median rank 4); then people with disabilities (median rank 5). Respondents' relatively high prior involvement with people with mental illness is unsurprising: Just under one in five Queenslanders (17\%) report having a long-term mental illness (lasting six months or more) (ABS, 2015), and incidence of mental illness has been shown to be higher among tertiary students (Baik et al, 2017), and significantly higher among performing artists (Live Performance Australia, 2015), than among the general Australian population. Roughly the same proportion of Queenslanders (18\%) report having a disability (ABS, 2017a); and 16\% of the Queensland population is 65 years of age and over (ABS, 2016b). At even higher representation, over one in five Queenslanders (22\%) was born overseas, and nearly one in three (31\%) had at least one parent born overseas (ABS, 2016a): students' engagement with culturally diverse people may therefore be expected too. While the lack of rigorous data makes it difficult to gauge the number of LGBTIQ and gender-diverse people in Queensland, it is estimated that $11 \%$ of the Australian population are of "diverse sexual orientation, sex or gender" (Department of Health, 2015).

The groups ranking lowest in terms of prior student engagement were prisoners (median rank 10), refugees (median rank 9), Muslim people (rank 8), and Indigenous Australians (median rank 6). The low levels of interaction with prisoners is unsurprising given the social challenges of engaging with this group (outside of family contexts), and the low prevalence relatively to the total Queensland population $(0.2 \%)$ (ABS, $2017 \mathrm{~b})$. The proportion of Queenslanders identifying as Aboriginal and/or Torres Strait Islander (4\%) or Muslim (under 4\%) is also low comparative to the groups referred to in the previous paragraph (ABS, 2017c).

Respondents were also asked which of those same groups of people they would most like to engage with, now or in the future (Box 4). Interestingly, no single group stood out as being highly ranked 
across the whole group: students appeared to have highly variable preferences. In particular, the most variation in rankings (5 or 5.5 Inter-Quartile Range [IQR]) was given to Australian Indigenous people, the elderly, and $L G B I T Q$ / gender diverse people. The most consistent ranking was low, and allocated to prisoners (IQR $=3.5$ ). The highest desired level of engagement was with culturally diverse people or people with mental illness (median rank 4, upper quartile ${ }^{5}$ rank 2). These were closely followed by several groups (median rank 5): Australian Indigenous (upper quartile rank 2); LGBITQ / gender diverse people, those from low socio-economic backgrounds, and refugees (all upper quartile rank 3); and those with disabilities (upper quartile rank 4). Responses indicated a lower desired level of engagement with people who are elderly (median rank 6) or those who are Muslim (median rank 7), and a very low desired level of engagement for prisoners (median rank 10). In comments, respondents also expressed interest in engaging with people from 'oppressed sub-cultures' (R34), young people aged 12-25 (R16), and 'other minority groups in other countries' (R24).

To facilitate comparison, Boxes 3 and 4 present these two sets of rankings — of students' prior engagement, and desired future engagement— - side by side.

\section{Box 3: In order of median rank, respondents reported prior engagement with:}

3. People with mental illnesses

4. LGBTIQ or gender-diverse people; Elderly people;

People from culturally diverse backgrounds;

People from low socio-economic backgrounds

5. People with disabilities

6. Australian Indigenous people

8. Muslim people

9. Refugees

10. Prisoners

\section{Box 4: In order of median rank, respondents reported desired future engagement with:}

4. People from culturally diverse backgrounds;

People with mental illnesses

5. Australian Indigenous people;

LGBITQ or gender-diverse people;

People from low socioeconomic

backgrounds;

Refugees;

People with disabilities

6. Elderly people

7. Muslim people

10. Prisoners

In general, a higher level of previous engagement with a specific group of people correlated with respondents' greater desire to engage with that group. This was true in the case of Australian Indigenous people, the elderly, LGBTIQ or gender diverse people, Muslim people, and those with mental illness. The correlation was not always neatly linear, however: for people from low socioeconomic backgrounds, respondents expressed higher desired levels of engagement if they had low or high previous engagement, but low desired levels of engagement if they had moderate previous engagement. In some cases, desired level of engagement was higher for those respondents whose previous levels of engagement with that group of people were lower; and sometimes conversely, desired levels of engagement were lower for respondents whose previous levels of engagement with a given group were higher. These findings suggest that students' engagement with certain groups of people often, but do not always, lead to their desire for ongoing engagement with that group. In the educational context, it should not be assumed that a given social engagement initiative will lead to students wanting to continue involvement with the respective social group into the future.

\footnotetext{
${ }^{5}$ The 'upper quartile' is the median of the upper half of the data set.
} 
Have engaged with people who:
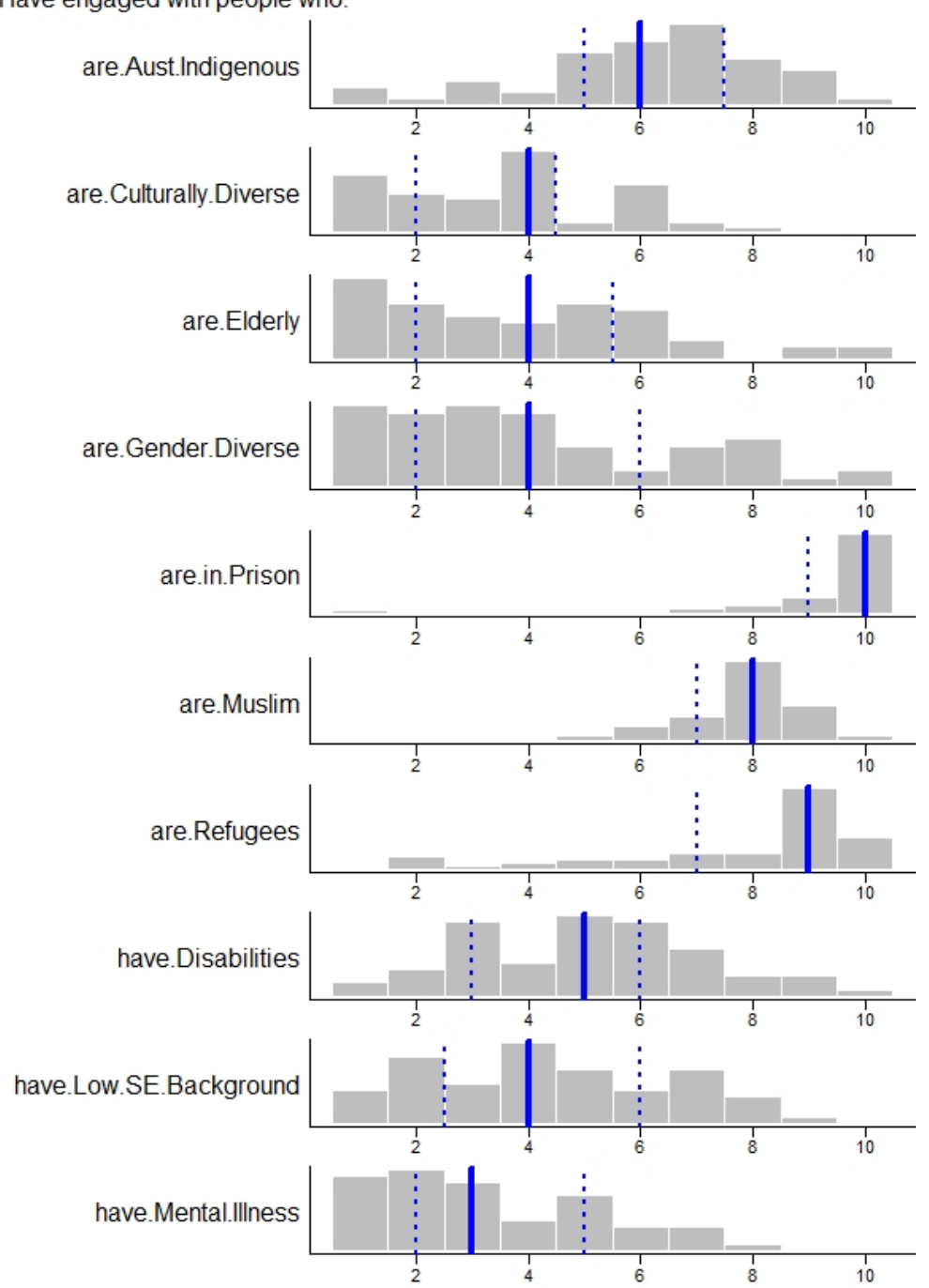

Would like to engage with people who:

are.Aust.Indigenous
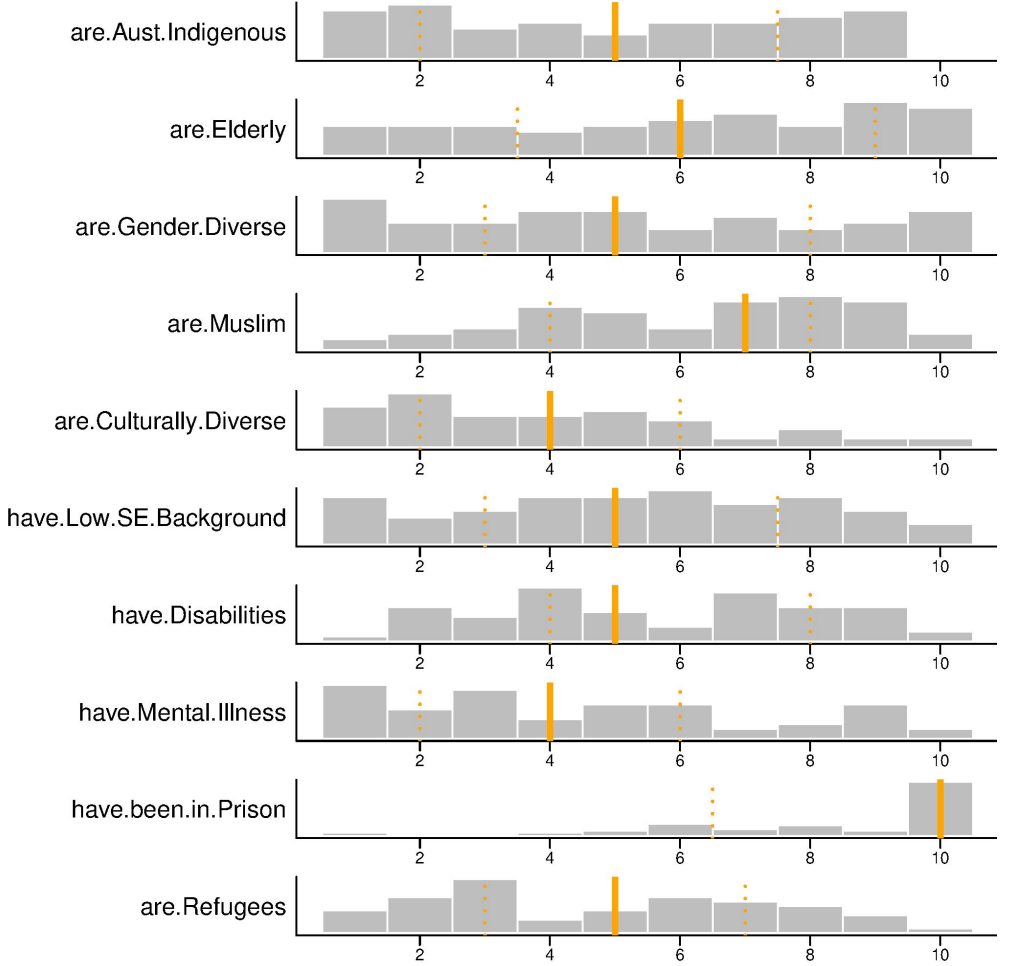
Figure 3. Histogram of relative frequency (y-axis) of ranks (x-axis) from 1 to 10 in responses for (a) 'previous engagement with' and (b) 'future desired engagement with'. Median is shown with a thick vertical line, and lower and upper quartiles with dashed vertical lines.

Figure 3 shows that students' levels of current engagement with these groups of people are much more polarised than, and mostly quite different from, their desired future levels of engagement with those same groups. These desired levels of engagement do not correspond in general with the issues which respondents identified as being of most interest to them, about which they are most informed, and with which they have had most engagement to date. This suggests an opportunity for re-orienting topics of awareness-raising activities, and perhaps increasing student agency for choosing topics, given the wide variation in students' future desired engagement across the groups.

\section{Implications for Educators and Institutions}

This research generates some preliminary insights into the social interests and levels of social awareness and engagement among a small sample of undergraduate students at one Australian tertiary music institution. One finding emerges clearly: that the picture is a complex one. Even within this single institution, students have widely varying levels of interest and engagement in particular social issues; widely varying previous experiences with certain social groups of people; and even more widely varying degrees of desire to engage with those groups. How interested and informed students are about particular social issues is sometimes strongly correlated, sometimes only weakly. Previous engagement with particular social groups often, but not always, means that students wish to engage with those groups further. Nuances and complexities like these are made visible through a statistical analysis of the survey data; they would be difficult to ascertain from a purely qualitative approach. As mentioned earlier, given the small and intra-institutional sample size, we make no claims about the generalizability of the data across institutional contexts, or even across the student population at the institution in question. Yet the findings presented above seem to suggest that future, more indepth studies within this institution and across others may generate useful insights into students' social experiences, perspectives, and intentions as musicians, with possible implications for the nature and degree of local institutional efforts to provide a more socially engaged, world-relevant tertiary music education. Incorporating the student perspective into educational decision-making could lead to more relevant, appropriate, targeted and effective socially engaged curricular activities and thus better learning outcomes for students. In turn, this educational benefit could be expected to result in social benefit too, as students graduate and forge careers and lives as musicians with better-developed senses of social awareness, engagement and responsibility (Grant, 2019).

However, even if this research were to be expanded, it is still not directly obvious how its findings could or should practically inform learning and teaching. This matter is a complex and substantial one, which warrants dedicated research in itself (and is beyond the scope of this article to address in depth). For example, should students be encouraged or obliged to develop their knowledge of those social issues about which they have little current interest or understanding (such as Australian Indigenous affairs, in the cohort under study here), or should they rather be particularly encouraged to further explore those social issues that especially interest them? Is it a university's responsibility to educate students about issues of social import as a core part of a tertiary education, or, in the interests of a student-centred, student-led curriculum, should it rather cater primarily to the interests of students themselves, even if these are niche or limited in social engagement terms? In whose best 
interests is it to offer students educational opportunities to engage with marginalised groups of people with whom they have had very little prior experience (refugees, prisoners)? What educational, ethical and moral considerations arise from attempting to educate students about social groups whose affairs hold 'very little' or 'no' interest to them (Muslim people, elderly people, Australian Indigenous people)? To at least some degree, these philosophical questions necessitate judgements of value, and as such may best be debated and negotiated among educators within local institutional contexts. That said, it will be important that the consequences of such discussions - including any curricula changes and their impact on students, the institution, and society - be the subject of evidence-based research too.

How best to integrate a social and ethical component into the tertiary music curriculum is therefore a crucial question arising from this research. Some scholar-pedagogues argue that students should first recognise and practice negotiating "the tensions between their personal and social identities" within the classroom before effectively negotiating them in the world (Zinck, 2009, pp. 343-4). Inviting guests with diverse musical and life perspectives and experiences into lecture spaces, for example, could help students challenge accepted norms (Vaugeois, 2009, p. 16). As a way of maturing students' social awareness and understanding of social (in)justice, Bachen and colleagues (2015) suggested an integrated approach to improving tertiary learning for social justice: namely, a combination of curricular experiences, community engagement activities, and global engagement activities. Offering new learning activities, whole courses or extra-curricular opportunities that enable students to develop their social awareness and engagement as musicians is one possible approach.

However, experiential or not, "surface change" through "additive means" (Campbell et al., 2014, p. 57 ) is only one step in the right direction. Additive changes also need to be sustained and supported by "fundamental changes in priorities, values, [and] perspectives" across the tertiary music sector (Campbell et al., 2014, p. 57): changes that fully acknowledge the social, political, moral and ethical implications of making and experiencing music; that are sufficiently embedded in the curriculum so that all students encounter social justice-oriented thinking (at least to some degree) through the course of their studies; and that reflect a commitment of music educators and institutions to teach, embrace, and exemplify values of social awareness, engagement, justice and equity (Reimer, 2007). The educational potential of such socially relevant initiatives is considerable, as prior studies show. Baxter (2007) found that after participating in a course about music education for social justice, tertiary music students felt that social justice (and, likewise, social awareness) was more central to a music education than they had previously thought. The curricular units developed by the participating students themselves were strategies for teaching and learning social justice through music, and teaching and learning music through social justice. In this way, as Baxter's research shows, music can be performed through the lens of social justice, while social justice can be performed through the lens of music - a possibility worthy of consideration by tertiary music students and tertiary music educators.

This study represents a small step toward providing a stronger evidence-based foundation for recent efforts toward a socially engaged vision of music education. Expanding the breadth and the depth of this research to a greater number of student participants across tertiary music institutions could ensure a stronger foundation for discussions and decisions - already well underway in many institutionsabout how to develop and implement a socially and ethically oriented tertiary music curriculum that is suited to students' interests and experiences. In tandem with research that offers a such a studentoriented perspective, further research is needed about viable pathways toward institutional cultural 
change that would see socially and ethically guided considerations sitting at the core of educational and institutional priorities, values, and perspectives in music (Campbell et al., 2014). In many institutions, this ideological shift also appears to be underway.

\section{Acknowledgements}

This research project was supported by a Queensland Conservatorium Research Centre Seed Grant.

The Griffith University research team comprised the first-named author as project leader, Professor Brydie-Leigh Bartleet, Professor Gemma Carey, Dr Meta Weiss, and Dr Naomi Sunderland, with the second-named author as statistical expert and advisor. Research assistance was provided by Teresa Kunaeva and Mathew Klotz. External advisor Professor Dawn Bennett (Curtin University) provided input on design and data collection. Thank you to all these and to the participating students.

\section{References}

Allsup, R. E., \& Shieh, E. (2012). Social justice and music education: The call for a public pedagogy. Music Educators Journal, 98(4), 47-51.

Arts Queensland (2015). Arts and disability. Retrieved from https://www.arts.qld.gov.au/aq-blog/artspractice/arts-and-disability

Australian Bureau of Statistics. (2015). National health survey: First results, 2014-2015 (Catalogue No. 4364.0.55.001). Retrieved from http://www.abs.gov.au/ausstats/abs@.nsf/mf/4364.0.55.001

Australian Bureau of Statistics. (2016a). Census of population and housing, 2016 (Catalogue No. 2001.0). Retrieved from http://www.abs.gov.au/census

Australian Bureau of Statistics. (2016b). Census of population and housing, 2016 (Catalogue No. 2001.0). Retrieved from http://www.abs.gov.au/census

Australian Bureau of Statistics. (2017a). Disability, ageing and carers, Australia: Summary of findings, 2015 (Catalogue No. 4430.0). Retrieved from http://www.abs.gov.au/ausstats/abs@.nsf/mf/4430.0

Australian Bureau of Statistics. (2017b). Prisoners in Australia, 2017 (Catalogue No. 4517.0). Retrieved from http://www.abs.gov.au/ausstats/abs@.nsf/mf/4517.0.

Australian Bureau of Statistics. (2017c). Census: Aboriginal and Torres Strait Islander population [Media Release]. Retrieved from http://www.abs.gov.au/ausstats/abs@.nsf/MediaRealesesByCatalogue/02D50FAA9987D6B7CA258 14800087E03?OpenDocument

Ayers, W., Quinn, T. M., \& Stovall, D. (Eds.). (2009). Handbook of social justice in education. New York and London: Routledge.

Bachen, C., Brewster, A., Guerra-Sarabia, R., Merritt, J., \& Schneider, J. (2015). Putting social justice at the center: Assessing social justice learning outcomes as a result of classroom, community, and cocurricular experiences. Retrieved from http://assessmentinstitute.iupui.edu/overview/institutefiles/2015-institute/monday-2015/brewster_2015.pdf

Baik, C., Larcombe, W., Brooker, A., Wyn, J., Allen, L., Brett, M., Field, R. \& James, R. (2017). Enhancing student mental wellbeing: A handbook for academic educators. Melbourne: University of Melbourne. Retrieved from http://www.unistudentwellbeing.edu.au

Bartleet, B.-L., Sunderland, N., \& Carfoot, G. (2016). Enhancing intercultural engagement through service learning and music making with Indigenous communities in Australia. Research Studies in Music Education, 38(2), 173-191. https://doi.org/10.1177/1321103X16667863 
Baxter, M. (2007). Global music making a difference: Themes of exploration, action and justice. Music Education Research, 9(2), 267-279.

Benedict, C., Schmidt, P., Spruce, G., \& Woodford, P. (Eds.). (2015). The Oxford handbook of social justice in music education. New York: Oxford University Press.

Campbell, P., Myers, D., Sarath, E., Chattah, J., Higgins, L., Levine, V., ... Rice, T. (2014). Transforming music study from its foundations: A manifesto for progressive change in the undergraduate preparation of music majors: report of the task force on the undergraduate music major. Unpublished document, The College Music Society, November 2014. Retrieved from http://www.mtosmt.org/issues/mto.16.22.1/manifesto.pdf

Creswell, J. W. (2009). Mapping the field of mixed methods research. Journal of Mixed Methods Research, 3(2): $95-108$, DOI: $10.1177 / 1558689808330883$

Cleveland, W. S. (1985). The Elements of Graphing Data, Vol. 2. Monterey CA: Wadsworth Advanced Books and Software.

Department of Health. (2015). National lesbian, gay, bisexual, intersex and transgender (LGBTI) ageing and aged care strategy. Retrieved from https://agedcare.health.gov.au/older-people-their-families-andcarers/people-from-diverse-backgrounds/national-lesbian-gay-bisexual-transgender-and-intersexlgbti-ageing-and-aged-care-strategy

Dragne, C. (2007). Background document for the University of Victoria Task Force on Civic Engagement. Retrieved from http://dspace.library.uvic.ca/handle/1828/1806

Elliot, D. J. (2007). "Socializing" music education. Action, Criticism, and Theory for Music Education, 6(4), 60-95.

Elliott, D. J. (2012). Another perspective: Music education as/for artistic citizenship. Music Educators Journal, 99(1), 21-27.

Elliott, D. J., Silverman, M., \& Bowman, W. (Eds.). (2016). Artistic citizenship: Artistry, social responsibility, and ethical praxis. New York: Oxford University Press.

Fosnacht, K., Sarraf, S., Howe, E., \& Peck, L. K. (2017). How important are high response rates for college surveys? The Review of Higher Education, 40(2), 245-265. doi:10.1353/rhe.2017.0003

Frierson-Campbell, C. (2007). Without the 'ism: Thoughts about equity and social justice in music education. Music Education Research 9(2), 255-265.

Gibson, W. J., \& Brown, A. (2009). Working with qualitative data. London: SAGE. doi: $10.4135 / 9780857029041$

Grant, C. (2018). Developing global citizenship in tertiary performing arts students through short-term mobility programs. International Journal of Education and the Arts, 19(15), 1-25. Retrieved from http://www.ijea.org/v19n15/

Grant, C. (2019). What does it mean for a musician to be socially engaged? How undergraduate music students perceive their possible social roles as musicians, Music Education Research, 21(4), 387398, DOI: $10.1080 / 14613808.2019 .1626360$

Greene, M. (1995). Releasing the imagination: Essays on education, the arts, and social change. San Francisco, CA: Jossey-Bass.

Griffith University (2017). Academic Plan 2017-2020. Brisbane, Australia: Griffith University. Retrieved from https://www.griffith.edu.au/about-griffith/corporate-governance/plans-publications

Gude, O. (2007). Principles of possibility: Considerations for a 21 st-century art \& culture curriculum. Art Education, 6(1), 6-17. doi: 10.1080/00043125.2007.11651621 
Hess, J. (2019). Singing our own song: Navigating identity politics through activism in music. Research Studies in Music Education, 41(1), 61-80. https://doi.org/10.1177/1321103X18773094

Liamputtong, P. (2011). Focus group methodology: Principles and practice. London: SAGE. doi: $10.4135 / 9781473957657$

Live Performance Australia (2015). Study highlights high prevalence of mental ill-health in live performance industry. Retrieved from http://liveperformance.com.au/Heads-Up-mental-health

Low-Choy, S., Riley, T., \& Alston-Knox, C. (2017). Using Bayesian statistical modelling as a bridge between quantitative and qualitative analyses: Illustrated via analysis of an online teaching tool. Educational Media International 54(4), 317-359.

Miettinen, L., Gluschankof, C., Karlsen, S., \& Westerlund, H. (2018). Initiating mobilizing networks: Mapping intercultural competences in two music teacher programmes in Israel and Finland. Research Studies in Music Education, 40(1), 67-88. https://doi.org/10.1177/1321103X18757713

Nair, C. S., Adams, P., \& Mertova, P. (2008) Student engagement: the key to improving survey response rates. Quality in higher education, 14(3), 225-232. doi: 10.1080/13538320802507505

Nichols, J., \& Sullivan, B. M. (2016). Learning through dissonance: Critical service-learning in a juvenile detention center as field experience in music teacher education. Research Studies in Music Education, 38(2), 155-171. https://doi.org/10.1177/1321103X16641845

Nyland, J. (2017). Opinion: Education in this brave new world demands meaningful human contact. Campus Review, July 10, 1-4. Retrieved from https://www.campusreview.com.au/2017/07/opinioneducation-in-this-brave-new-world-demands-meaningful-human-contact/

Pantić, N. (2017). An exploratory study of teacher agency for social justice. Teaching and Teacher Education, 66, 219-230.

UNHCR (2018). About us: Figures at a glance. Retrieved from http://www.unhcr.org/en-au/figures-at-aglance.html

Vaugeois, L. (2009). Music as a practice of social justice. In E. Gould, J. Countryman, C. Morton \& L. S. Rose (Eds.), Exploring social justice: How music education might matter (Vol. 4, pp. 2-22). Toronto: Canadian Music Educators' Association.

Wani, T. A., \& Nadeem, N. A. (2016). Social awareness among higher education teachers. International Journal of Scientific Research and Education, 4(2), 4914-4919.

Whyte, B. (2009). The heart of the matter: A pre-service teacher's narrative on coming to a social justice oriented vision for music education. In E. Gould, J. Countryman, C. Morton, \& L. S. Rose (Eds.), Exploring social justice: How music education might matter (Vol. 4, pp. 317-324). Toronto: Canadian Music Educators' Association.

Wiersma, W. (2013). The validity of surveys: Online and offline. Oxford Internet Institute, 18(3), 321-340 (1-13). Retrieved from https://pdfs.semanticscholar.org/cf8b/bec79781602ebe2125e4be5cef3669b7d9e6.pdf

Zinck, A. M. (2009). Toward a values-driven model of course design. In Gould, E.; Countryman, J.; Morton, C.; \& Stewart Rose, L. (Eds). Exploring Social Justice: How Music Education Might Matter, pp. 343-358. Toronto: Canadian Music Educators' Association. 